\title{
Principles of effective functioning of training system of future teachers of natural science and mathematics for STEM technologies usage
}

\author{
Nataliia Valko ${ }^{1, *}$ and Viacheslav Osadchyi ${ }^{2, * *}$ \\ ${ }^{1}$ Kherson State University, 27 Universytetska Str., Kherson, 73003, Ukraine \\ ${ }^{2}$ Bogdan Khmelnitsky Melitopol State Pedagogical University, 20 Hetmanska Str., Melitopol, 72300, Ukraine
}

\begin{abstract}
The issue of the training of future teachers of natural science and mathematics to using STEM technologies was discussed on the basis of the system of scientific analysis. The article describes several severities of the process of training future teachers of natural science and mathematics and organization of making use of STEM technologies based on project priorities and application-oriented study methods, connected with modern technologies and also supplying them by social connection in a professional environment. The assembly of the principles of the effectiveness of the training system referred to above shall be defined and described in the following paragraphs.
\end{abstract}

\section{Introduction}

Modern civilizational processes, both in Ukraine and around the world, show a strong increase in the influence of information and technological factors on social communication. Besides, the role of these processes is gradually increasing in almost all social and manufacturing areas, specifically in education. Just in this area, rapid modernization and reform of the project and objective of academic influence are taken into account. STEM, which is also called a unique educational phenomenon, which for its form integrates global achievements into science, technology, engineering, and modern mathematics, is the part of this point. This fact affirms the need to improve the vocational training of future teachers of natural sciences and mathematics, who can be oriented towards creating the will to use the technological issues of STEM education. In order to ensure the effectiveness of the training system for teachers of natural science and mathematics in the use of STEM technologies in the educational process, it is necessary to define and scientifically support the scientific basis of a set of principles for its application. The system of preparing teachers of natural science and mathematics for the application of STEM technologies must meet the needs of society and solve the problems it faces. These challenges are common to all countries, including Ukraine [1-7]:

- reduced interest in the exact profession of science and engineering,

- growing demand for qualified technicians and researchers,

\footnotetext{
*e-mail: valko@ksu.ks.ua

**e-mail: osadchyi@mdpu.org.ua
}

- the development of production on the basis of the introduction of the latest equipment, technologies, and materials,

- increasing employers' needs in terms of technological qualifications of workers,

- the development of STEM industry and the emergence of new professions in this field.

\section{Related Works}

The training process of future teachers of natural science and mathematics in the context of the application of STEM education also has certain features.

First, it is impossible to implement interdisciplinarity as long as the future teacher of natural sciences and mathematics does not acquire an in-depth knowledge of the disciplines from which integration takes place [8], so in the program of training teachers of natural sciences and mathematics to use the basic disciplines STEM technologies must precede all others, and sufficient time must be given to master them [9-11].

Secondly, there is a need for practical experience, especially in the implementation of project activities [12, 13]. This experience is acquired by the future teacher in the realization of different exercises, through independent work in laboratory classes and practices, in different types of repetition [14], as well as through the realization of project activities during the training, which encourages them to think about the problems related to their training [15]. As a result, future teachers acquire teamwork experience and research approach to learning the world around them, thus forming the appropriate components of the readiness studied. As a result, the project activity should "permeate" the entire process of preparing teachers 
of natural science and mathematics for the use of STEM technologies.

Thirdly, it is very important to socialize and adapt to the future teachers of natural science and mathematics in the professional environment, which will enable him to form appropriate professional behavior, compare himself or herself to other teachers, and encourage further learning. Therefore, in the training of teachers of natural science and mathematics for the use of STEM technologies, it is necessary to ensure appropriate social interaction in the professional environment.

Fourthly, the effectiveness of training of teachers of natural science and mathematics depends entirely on the level of training of its sphere of the motivation of value [16-20]. Therefore, it is necessary to create an appropriate motivational fund, stimulating their psychological readiness to learn, as well as to form an active and positive attitude towards technology in future professional activities.

The concept of "learning principles" is considered to be "a system of basic teaching requirements for the organization of the educational process, which ensures its effectiveness" [21]. At the same time, it is fundamental ideas, initial provisions determining the content, forms, and methods of educational work according to the purpose of education and the laws of the educational process $[22,23]$.

Thus, the principles of education will be regarded as regulations that determine the requirements for the organization of the training system for teachers of natural science and mathematics to the use of STEM technologies, whose compliance ensures its effectiveness.

\section{Results of the research}

In order to determine all the principles for the organization of the training system for teachers of natural science and mathematics for the use of STEM technologies, it is necessary to take into account the requirements of the principles as a scientific category [24]:

- the formulation of the principles should take into account objectively existing pedagogical models and trends objectively existing in the development of the phenomenon under consideration,

- all principles should aim at solving the research problem while determining its general direction, guidelines, and strategy for the implementation of the research process,

- the principles should act as a system training factor affecting all components of the training system for teachers in natural sciences and mathematics and ensuring their functioning as a system,

- the principles should reveal various aspects of the preparation of future teachers of natural science and mathematics for the application of STEM technologies,

- each principle must be complementary to the others.

In the context of our study, is interesting, which, depending on the key elements and stages of the education process, has identified principles that will contribute to the effective implementation of STEM education in Ukraine [25]:

- aims and objectives of training (focusing on practical purposes and clarity),

- involvement of students (personalization, interaction, and outcome),

- training of learning contents (interconnection, integration and modularity),

- organization of training (practice training, technology, continuity, and adaptation).

Based on the research methodology outlined, as well as on the basis of our own vision of the phenomenon studied, we have identified a set of principles that will contribute to the effective implementation of the training system for future teachers of natural science and mathematics to apply STEM technology in professional activities. Consider these principles in greater detail and determine the requirements for the implementation of the training system for future teachers of natural science and mathematics for the use of STEM technologies in professional activities.

1. Thus, the principle of personalization in the training of the future Masters in Science and Mathematics for the use of STEM technology in professional activities implies taking into account the individual psychological characteristics, age and other individual characteristics (personal experience, feelings, emotions, actions) of any future teachers of natural science and mathematics. According to this principle, every future teacher of natural sciences and mathematics actively participates in the construction of a personal educational path according to his own goals and abilities, feels an individual, a person who is the subject of learning [26].

At the same time, the attention of teachers should be focused not only on the formation of the knowledge of the future teacher, but also on taking into account the social and emotional aspects of his personality, ensuring the awareness of his both "weak" and "strong" characteristics, describing the areas of personal development. The principle of personalization also implies that communication and interaction between all participants in training take place in partnership [27-29]. Therefore, during training sessions and laboratory and practical work, any future teachers of natural science and mathematics should participate in the study of STEM according to their needs and abilities. The application of the principle of personalization makes it possible to optimize the professional training process of future teachers of natural science and mathematics on the basis of the personal needs and motivations of each future teacher, ensuring their effectiveness and efficiency.

2. The principle of conscious cognitive activity implies the formation of future teachers of natural science and mathematics a conscious attitude towards learning, understanding the general objective 
of specific classes and tasks to achieve this objective, as well as the development of a strong desire for self-knowledge and self-improvement. It offers a meaningful and creative approach to mastering the knowledge necessary for the application of STEM technologies in other professional activities. The conscious cognitive activity of the future teachers of natural science and mathematics is facilitated by: the explanation of the purpose and tasks of the discipline and its modules; the importance of discipline (special courses) in solving the problems of the future professional activity; the use in the educational process of tasks that encourage analysis, synthesis, generalization, induction, deduction; the creation of positive emotions.

According to this principle, future teachers of natural sciences and mathematics should not be passive students, but should be interested in the educational process that they are consciously learning $[30,31]$. Thus, taking into account the principle of conscious cognitive activity in the process of preparing future teachers of natural science and mathematics for the application of STEM technologies in professional activity, it is sent to train future teachers of conscious attitude towards an educational process as a process of knowledge of the surrounding reality, and also of conscious understanding of the material of the educational disciplines of the professional preparation program.

3. The principle of self-organization presupposes the need to change in the process of preparing the role of the future teachers of natural science and mathematics from "the one who teach" to "the one who learns". In this case, the self-organization of the future teacher is directly linked to his/her selfeducation $[32,33]$ - one of the most important organizational forms of the educational process, which takes place without the participation of teachers and is led by the individual.

This principle is closely linked to the principle of conscious cognitive activity and is due to the need for future teachers of natural science and mathematics to organize their activities not only during training but also in other professional activities. The principle of self-organization also determines the need for the self-updating of future teachers of natural sciences and mathematics and the formation of their desire to identify and develop their skills.

In this case, self-updating provides the future teacher's perception of reality, the objective of its evaluation system, the training of self-regulation capacity, self-analysis and self-control in educational activities [34].

Thus, taking into account the principle of selforganization in the process of training future teachers of natural science and mathematics for the application of STEM technologies in professional activities, it contributes to the activation, optimization and improvement of the process of training and rationalization of the educational activities of future teachers. The effectiveness of each teacher's educational activities depends mainly on personal preferences and efforts [35].

4. The principle of the formation of valuable guidelines presupposes the need to train future teachers of natural science and mathematics of relevant values, combined with the use of STEM technologies in future professional activities.

Compliance with this principle is extremely important for our study, because it is the value orientations that reflect the conscious attitude of future teachers of natural science and mathematics towards new professional activities in general and ensure their attention to the use of STEM technologies in particular. At the same time, the value guidelines also determine the personality orientation of the future teacher in order to creatively solve the problems of professional activity, as well as the constant improvement and development of self-education in the field of STEM education.

It is no less important that individual values and students' knowledge are determined by each other. In other words, knowledge reflects the objects and phenomena of reality, and the orientations of value the individual's attitude towards them. Thus, in the structure of the guidelines of the value of personality act as a kind of coordination center, this determines their behavior and attitude towards the social environment [36, 37].

In view of the principle of the formation of valuable guidelines training in the process of preparing future teachers of natural sciences and mathematics for the use of STEM technologies in professional activities, it will ensure awareness of the dominant need for STEM technologies and allow them to set appropriate priorities to solve various professional tasks related to the implementation of STEM education.

5. The principle of cooperation and mentoring in the study process involves the organization of intersubject relations, including teamwork and continuity in education, which is achieved through the exchange of experience in the use of STEM technologies in professional activities between teachers of free economic practice, experienced teachers and future teachers of natural sciences and mathematics.

On the basis of this principle, all actors should cooperate, form a coalition of more and less experts, actively share experience on the specificities of the practical application of STEM technologies on the basis of partnership, volunteering, transparency, openness, equality and mutual accountability $[38,39]$.

Therefore, taking into account the principle of cooperation and mentoring in the process of preparing 
future teachers of natural science and mathematics for the application of STEM technologies in professional activities, it will ensure the participation of teachers-practices experienced in this process, creating inter-subjective links between them and future teachers of natural science and mathematics, as well as intensifying the exchange of experience in the application of STEM technologies in professional activities.

6. The principle of dialogic in the study process [40] presupposes the exceptional importance of dialogue for the formation of the future teachers of natural science and mathematics.

On the basis of this principle, the appropriate training of teachers of natural science and mathematics for the use of STEM technologies in professional activities can only be carried out through dialogue with free economic education teachers, expert-practical teachers and fellow graduates. The content of this dialogue is the exchange of experience in the application of STEM technologies and the joint production of new knowledge in this area.

It should be noted, however, that this principle does not provide for equality between the teacher, the teacher-practice and higher education, due to differences in age, life experience and different social roles [41]. Nevertheless, the principle of dialogic presupposes sincerity, mutual respect and tolerance for other people's opinions. Therefore, taking into account the principle of dialogic in the process of preparing future teachers of natural science and mathematics for the use of STEM technologies in professional activities, it will offer the possibility of exchanges between teachers of free economic sciences, teachers of natural sciences and mathematics and professionals as individuals and as future teachers.

7. The principle of integration implies the integration into the content of the training program of disciplines related to the use of STEM technologies and STEM education. In this case, integration should not be just a combination, but the interpenetration of two or more STEM disciplines. This will ensure the formation of an inclusive vision of future teachers of natural science and mathematics on STEM education and the use of STEM technologies in other professional activities.

According to this principle, the learning content should be linked to the STEM industry, its main disciplines in each course of study. The organic combination of the content of the training program for future STEM education informatics teachers, STEM technologies, STEM disciplines and other vocational and pedagogical orientation courses around a theme will provide an integral perception of educational material on different sides, multiform knowledge of STEM education, the development of criti- cal thinking and value orientations important to the STEM industry.

8. The principle of transdisciplinarity is linked to the principle of integration and implies that the content of the training of teachers of natural science and mathematics for the application of STEM technology goes beyond a particular discipline, permeating different disciplines, which will transfer knowledge from one discipline to another.

Implementation of this principle is associated with the need to train in teachers of natural science and mathematics a meta-subject vision of the disciplines of the STEM industry, which is essential for STEM education and the use of STEM technology. To form a meta-subject vision in the training process of future teachers, it is necessary to use methods such as analysis, synthesis, generalization, definition, distribution, classification, etc.

In the maintenance of disciplines, it is necessary to provide: the transition from simple to difficult subjects, from concrete to general and, on the contrary, the conduct of theoretical of theoretical before those practices; methodologically justified alternation of theoretical and practical classes; the overall application of knowledge in the performance of various tasks.

Therefore, taking into account the principle of transdisciplinarity in the process of preparing teachers of natural science and mathematics for the use of STEM technologies, it provides effective training in the meta-subject vision of STEM education and STEM disciplines as a basis for the effective application of STEM technologies in subsequent professional activities.

9. The principle of the link between learning and life implies that the preparation content of future teachers of natural science and mathematics for the application of STEM technologies is correlated with the requirements of real life specialists.

According to this principle, during the development of any program of any discipline of training of future teachers of natural science and mathematics to its content, it is necessary to include topics intended to develop the required skills in the twenty-first century [42, 43].

At the same time, in forming this content, it is necessary to take into account the main tasks of the educational process in higher education, the specific vocational training tasks of teachers of natural science and mathematics, as well as the real possibilities of higher education.

Taking into account the principle of the link between learning and life in the process of preparing teachers of natural science and mathematics for the application of STEM technologies provides a consideration in the context of preparing real life requirements for professionals in the 21 st century. 
10. The principle of significance of learning outcomes to the individual implies that the expected outcomes and the purpose of preparing teachers of natural science and mathematics for the use of STEM technologies should individually include significant outcomes for each graduate educational outcome.

Based on this principle, each future teacher of natural sciences and mathematics seeks individual achievements in educational activities, because the personal results provide the meaning of any activity and the realization of one of the main needs - to succeed in learning, in professional activities and in life. No less important is the fact that the satisfaction of this need of the individual contributes to its self-up gradation, self-affirmation, increase the level of self-esteem and, in general, provides the humanization of the training process.

In order to implement this principle, it is necessary to create for future teachers of natural science and mathematics various successful situations in which they may experience a state of joy and satisfaction in achieving or overcoming the expected result [44].

The most effective thing for this is the use of problematic situations, the solution of which will allow the student of higher education to feel involved in what is happening in the classroom, as well as to increase the strength and efficiency of the knowledge acquired by him. A more comprehensive tool for creating successful situations is project technology, which aims to apply future natural science and mathematical disciplines teachers of existing factual knowledge and to acquire new knowledge.

Thus, taking into account the principle of significance of learning outcomes to the individual in the process of preparing future teachers of natural science and mathematics for the application of STEM technologies, it provides greater motivation for learning, allows the student to take advantage of educational activities, stimulates them to high learning, eliminates anxiety, uncertainty and low selfesteem, develops initiative, creativity and activity, as well as stimulates their self-organization and selfrealization.

11. The principle of feedback implies the need to obtain timely information on the results of the training of teachers of natural science and mathematics to use STEM technologies in the form of assessment, documentation and diagnostic results.

The implementation of this principle enables freelance teachers to determine the correction of their actions during teaching, to obtain information on the conformity of training with the expectations of future teachers, to identify the complications that arise during the training, as well as the "weaknesses" and gaps in their preparation for using STEM technology.

Feedback in training not only carries out semantic but also emotional functions. The semantic function determines the achievement by future teachers of natural and mathematical sciences of certain results of the formation according to the criteria of evaluation determined, and the emotional function allows to determine their state of mind during the formation and, if necessary, to eliminate negative trends in the relationship between the training subjects.

In order to provide feedback in the process of preparing teachers of natural science and mathematics for the use of STEM technologies, it is recommended to use anonymous questionnaires and reflections.

In particular, anonymous questionnaires are carried out either in the last lesson or after control of the module. This questionnaire provides much information on the effectiveness of certain teaching methods, students' satisfaction with the learning process and its results during the semester, as well as the level of achievement of the learning target and the expected results. The results of the questionnaire are taken into account, but not as a final evaluation of the teacher's work by future teachers [45]. During the reflection, which takes place constantly during the training, every future teacher of natural science and mathematics analyzes what is happening and draws its conclusions. Reflection helps the future teacher to achieve adequate self-esteem, to increase self-organization and self-motivation.

Thus, taking the principle of feedback into account in the training process of teachers of natural science and mathematics for the application of STEM technologies helps to understand the nature of the difficulties, gaps and "weaknesses" of this training, to determine the reasons for their occurrence, allowing the whole training process to be adjusted.

12. The principle of constant control implies the need for teachers, Methodists and curators working with future teachers of natural science and mathematics, regular and continuous diagnostic actions.

The control process consists of three main elements: establishment of standards; comparing the results with the established standards; and actions. According to this principle, in the training process it is necessary to evaluate not only the level of knowledge and skills, but also the level of training of other professionally significant personal characteristics which form the basis for future teachers of natural science and mathematics to apply STEM technologies in professional activities. This control will not only provide information on the initial state and final results of the preparation process studied, but also monitor current results. This principle is closely linked to the principle of feedback and determines the need to develop appropriate diagnostic tools to determine the level of preparation of the teachers of natural science and mathematics to use STEM technology for the relevant components of its content. 
Thus, taking into account the principle of constant control in the process of preparing teachers of natural science and mathematics for the application of STEM technologies shows the progress of the planned task system allows eliminating deviations and provides an adaptation to change.

We believe that the implementation of a set of principles mentioned above will in practice allow the implementation of an effective training system for future teachers of natural science and mathematics for the use of STEM technologies in professional activities.

To gain experience, a future teacher must participate in the process of creative, search activity, since the experience of creative activity cannot be conveyed by stories, indications of the process itself, they are carried out together with students.

To develop the creative abilities of students, it is necessary to involve them in a specially organized educational scientific and cognitive process, which is a model of the scientific process of cognition. In this aspect, the use of interactive teaching methods provides planned results if students become carriers of specific roles; simulation-game situations create a real environment, the content is based on specific practical material that reflects the content of professional activity, providing a combination of training with the professional development of future specialists.

Fulfillment of specific roles obliges students to analyze and make professionally significant decisions, increases the level of their professional competence, including pedagogical.

Based on the analysis of scientific sources and based on the author's vision of the features of the studied phenomenon, in the necessary and sufficient organizational and pedagogical conditions that ensure the effectiveness of the process of training future teachers of natural science and mathematics for the use of STEM technologies, the following are attributed:

1. Updating the content of professional training of future teachers of natural science and mathematics to use STEM technologies.

2. Implementation of STEM projects in robotics by future teachers of natural science and mathematics.

3. Ensuring in the course of training future teachers of natural science and mathematics of their social interaction in a professional environment.

An important role in the organization of the process of training future teachers of natural science and mathematics is played by complex methodological support, which requires the determination of the regulatory framework, information and material and technical support of the educational process.

Therefore, in the course of preparing for the application of STEM technologies in professional activities, future teachers of natural science and mathematics get acquainted with methodological recommendations, regulations, instructions and other normative acts of the educational process. First of all, they become familiar with the
"Typical list of learning tools and equipment for educational and general purposes for classrooms of natural and mathematical subjects of general educational institutions". Their use allows students to carry out design and research activities, to implement the tasks of modeling various processes and phenomena and consciously form qualitatively new transdisciplinary knowledge.

\section{Conclusions and future work}

On the basis of the study, we identified twelve principles, the respect of which will contribute to the effective implementation of the training system of future teachers of natural science and mathematics for the use of STEM technologies in professional activities. The set of principles that we define includes: the principle of personalization, the principle of conscious cognitive activity, the principle of self-organization, the principle of the formation of valuable guidelines, the principle of cooperation and mentorship, the principle of dialogic, the principle of integration, the principle of transdisciplinarity, the principle of the link between learning and life, the principle of significance of learning outcomes to the individual, the principle of feedback and the principle of constant control.

They create a proper basis for building a model for the training system of future teachers of natural science and mathematics for the use of STEM technologies.

\section{References}

[1] J.G. Dees, Journal of business ethics 111, 321 (2012)

[2] New ukrainian school: conceptual principles of secondary school reform (2016), https://mon.gov . ua/storage/app/media/zagalna\%20serednya/ nova-ukrainska-shkola-compressed.pdf

[3] M. Pietrocola, ed., Upgrading Physics Education to Meet the Needs of Society (Springer International Publishing, 2019)

[4] European Commission, Science Education in Europe: National Policies, Practices and Research (Education, Audiovisual and Culture Executive Agency, 2011), http://www . indire.it/lucabas/lkmw_ file/eurydice/sciences_EN.pdf

[5] I. Lovianova, D. Bobyliev, A. Uchitel, CEUR Workshop Proceedings 2433, 459 (2019)

[6] T. Kramarenko, O. Pylypenko, V. Zaselskiy, CEUR Workshop Proceedings 2547, 130 (2020)

[7] T. Kramarenko, O. Pylypenko, I. Muzyka, CEUR Workshop Proceedings 2643, 705 (2020)

[8] H. Jacobs, J. Borland, Gifted child quarterly 30, 16 (1986)

[9] N. Rashevska, V. Soloviev, CEUR Workshop Proceedings 2257, 192 (2018)

[10] I. Kholoshyn, O. Bondarenko, O. Hanchuk, E. Shmeltser, CEUR Workshop Proceedings 2433, 403 (2019)

[11] S. Semerikov, A. Striuk, L. Striuk, M. Striuk, H. Shalatska, E3S Web of Conferences 166 (2020) 
[12] O. Lavrentieva, I. Arkhypov, O. Krupskyi, D. Velykodnyi, S. Filatov, CEUR Workshop Proceedings 2731, 143 (2020)

[13] T. Kramarenko, K. Bondar, O. Shestopalova, Journal of Physics: Conference Series 1840, 012009 (2021)

[14] K. Osadcha, H. Chemerys, Ukrainian Journal of Educational Studies and Information Technology 5, 37 (2017)

[15] W. Melville, X. Fazio, A. Bartley, D. Jones, Journal of Science Teacher Education 19, 477 (2008)

[16] M. Kagan, in Introduction to culturology: Course of lectures (2003), pp. 6-14

[17] R. Santagata, J. Guarino, ZDM 43, 133 (2011)

[18] J. Hiebert, A.K. Morris, B. Glass, Journal of mathematics teacher education 6, 201 (2003)

[19] H. Sublette, Ph.D. thesis (2013)

[20] M. Moiseienko, N. Moiseienko, I. Kohut, A. Kiv, CEUR Workshop Proceedings 2643, 60 (2020)

[21] N. Volkova, Akademvidav 616, 2 (2007)

[22] A. Kuzminsky, V. Omelyanenko, Pedagogy (Znannia, 2007)

[23] S.O. Semerikov, I.O. Teplytskyi, V.N. Soloviev, V.A. Hamaniuk, N.S. Ponomareva, O.H. Kolgatin, L.S. Kolgatina, T.V. Byelyavtseva, S.M. Amelina, R.O. Tarasenko, Journal of Physics: Conference Series 1840, 012036 (2021)

[24] B. Siciliano, O. Khatib, Springer handbook of robotics (Springer, 2016)

[25] E. Smyrnova-Trybulska, N. Morze, P. Kommers, W. Zuziak, M. Gladun, Educational Robots in Primary School Teachers' and Students' Opinion about STEM Education for Young Learners, in International Association for Development of the Information Society, Paper presented at the International Conferences on Internet Technologies $\mathcal{E}$ Society (ITS), Education Technologies (ICEduTECH), and Sustainability, Technology and Education (STE) (Melbourne, Australia, Dec 6-8, 2016) (2016), https://eric.ed.gov/?id=ED571601

[26] H. Bembenutty, M.C. White, M.R. Vélez, Developing self-regulation of learning and teaching skills among teacher candidates (Springer, 2015)

[27] R.J. Ocker, G.J. Yaverbaum, Group Decision and Negotiation 8, 427 (1999)
[28] M. Marienko, Y. Nosenko, M. Shyshkina, CEUR Workshop Proceedings 2731, 341 (2020)

[29] M. Marienko, Y. Nosenko, A. Sukhikh, V. Tataurov, M. Shyshkina, E3S Web of Conferences 166 (2020)

[30] M.I. Sherman, Y.B. Samchynska, Information Technologies and Learning Tools 72, 121 (2019)

[31] S.L. Malchenko, Journal of Physics: Conference Series 1840, 012016 (2021)

[32] O. Triakina, O. Pavlenko, N. Volkova, D. Kassim, CEUR Workshop Proceedings 2257, 173 (2018)

[33] O. Glazunova, T. Voloshyna, A. Gurzhii, V. Korolchuk, O. Parhomenko, T. Sayapina, T. Semyhinivska, CEUR Workshop Proceedings 2732, 591 (2020)

[34] V. Osadchyi, H. Varina, E.H. Prokofiev, I. Serdiuk, S. Shevchenko, 2732, 634 (2020)

[35] N. Kushnir, N. Osypova, N. Valko, L. Kuzmich, 2732, 1152 (2020)

[36] T. Vdovychyn, Journal of Information Technologies in Education 8, 17 (2020)

[37] V.V. Osadchyi, N.V. Valko, N.O. Kushnir, Information Technologies and Learning Tools 75, 316 (2020)

[38] O. Kovshar, M. Baditsa, K. Suiatynova, International Journal of Engineering and Advanced Technology 9 , 4556 (2019)

[39] K. Vlasenko, O. Chumak, I. Sitak, I. Lovianova, O. Kondratyeva, Universal Journal of Educational Research 7, 1892 (2019)

[40] A. Abdula, H. Baluta, N. Kozachenko, D. Kassim, CEUR Workshop Proceedings 2643, 306 (2020)

[41] J. Cohen, L. McCabe, N.M. Michelli, T. Pickeral, Teachers college record 111, 180 (2009)

[42] N. Kushnir, Journal of Information Technologies in Education (ITE) 28, 147 (2014)

[43] I. Naumuk, N. Korzun, Ukrainian Journal of Educational Studies and Information Technology 6, 70 (2015)

[44] V. Osadchyi, N. Valko, L. Kuzmich, N. Abdullaeva, SHS Web of Conferences 75, 04014 (2020)

[45] V. Starosta, O. Popadich, Ukrainian Journal of Educational Studies and Information Technology 6, 16 (2018) 